\title{
THE DYNAMIC RELATIONSHIP BETWEEN HOUSE PRICES AND OUTPUT: EVIDENCE FROM US METROPOLITAN AREAS
}

\author{
Nicholas APERGIS a, Beatrice D. SIMO-KENGNE ${ }^{\text {b }}$, Rangan GUPTA ${ }^{\text {b, }}$, \\ Tsangyao CHANG ${ }^{\mathrm{c}}$ \\ ${ }^{a}$ Department of Banking and Financial Management, University of Piraeus, Greece \\ ${ }^{b}$ Department of Economics, University of Pretoria, Pretoria, 0002, South Africa \\ ${ }^{c}$ Department of Finance, Feng Chia University, Taichung, Taiwan
}

Received 21 January 2014; accepted 5 September 2014

\begin{abstract}
This paper investigates the long-run and short-term dynamics of 351 US metropolitan statistical area housing prices in relation to personal income. We apply a panel cointegration approach on annual data from 1993 to 2011 and find a long-run relationship between local house prices and per capita personal income. The causal direction is then assessed based on an autoregressive distributed lag specification that also accommodates for error-correction. Results from Granger-causality tests reveal the existence of a bi-directional causality between real house prices and real per capita personal income over both long and short-horizons. Our results continue to be robust, when our bivariate system is extended to include additional MSA-level (employment and population) and national-level variables (real stock price and mortgage interest rate). We conclude that changes in personal income can predict house price movements and vice versa.
\end{abstract}

KEYWORDS: Real house prices; Real personal income per capita; Panel cointegration; Panel causality

\section{INTRODUCTION}

Over the past decades, housing price appreciation has manifestly increased the total wealth of households in the United States (US). The 1998 Federal Reserve survey finds that $66.2 \%$ of US households are homeowners and housing investment represents $33 \%$ of households' net wealth (Kennickell et al. 2000). Recently, Iacoviello (2011) indicate that housing amounts approximately to $40 \%$ of households' asset and just under $50 \%$ of total wealth. Thus, house prices might be an important determinant of output. One reason lies in the fact that higher house prices encourage new constructions, leading to the increase of supplier activity and hence the economic performance. Likewise, housing market outcomes are expected to be driven by economic conditions as changes in the distribution of wealth are reflected in the distribution of prices including housing services (Hwang, Quigley 2006). Accordingly, higher income increases housing demand which raises the real estate prices. These inter-linkages are generally formalized in the

\footnotetext{
* Corresponding author. E-mail: rangan.gupta@up.ac.za
}

housing literature by assuming a stable long-run relationship between house prices and economic fundamentals (Abraham, Hendershott 1996; Meen 2002; Capozza et al. 2002; Nyakabawo et al. 2013).

The present study hypothesizes and tests the existence of a cointegrating relationship between house prices and income in a panel of 351 Metropolitan Statistic Areas (MSAs) over the period 1993 to 2011 . This sample period is driven by data availability in the public domain, which in turn, allows us to simultaneously cover the maximum possible number of MSAs, as well as, bulk of the housing boom/bust episodes, including the Great Recession, with possible significant gaps between these variables and their equilibrium values as a result of substantial volatilities. If house prices and income are linked by a stable long-run relationship, the two series are mean reverting so that any gap between the two variables is temporary; the tendency being to return to their long-term equilibrium (Gallin 2006). From a policy perspective, the cointegration between the two variables implies that fluctuations in house prices can pre- 
dict changes in income or vice versa depending on the direction of the causality.

Though some researchers, like Galin (2006), remain skeptical about the housing prices - economic growth nexus, many economists and policymakers commonly agree that house prices fluctuations play an important role in driving business cycle dynamics. This can be observed with the recent recession prompted by the collapse in the housing market or the strong housing market during the 2001 stock market crash which has been claimed to have saved the US economy from a severe recession (Miller et al. 2011). Historically, the trend of housing prices during 1994-1999 seems to follow growth in per capita income across the 351 MSAs in the sample. Real per capita personal income grew on average at $2 \%$ while real home prices rose just above 1\%. However, between 2000 and 2005, real house prices moved up rapidly across the panel; rising at roughly $4.5 \%$ per annum compared to less than $1 \%$ in real per capita personal income. This evolution contrasts the tendency towards the end of the sample period. Specifically, between 2006 and 2011, average real house prices decreased approximately at $4 \%$ despite the positive but slow average growth rate of $0.65 \%$ per annum in real per capita personal income. This suggests that lags and speed of adjustment might be crucial to understanding the dynamic relationship between the two variables.

House price adjustment impacts the real economy mostly through the wealth and/or collateral effects on consumption (Demary 2010; Miller et al. 2011). Based on the permanent income hypothesis, the wealth effect suggests that fluctuations in house prices affect homeowners expected lifetime wealth and thusly their desired consumption providing that consumption is smoothed throughout the projected life span. On the other hand, house price dynamics may also affect the liquidity constraints of homeowners, and hence the ability of homeowners to borrow for consumption purpose since housing is collateralisable. Given that consumption is the major component of output, house price changes are thus expected to affect the dynamics of output.

In contrast to the extensive literature on the spillover effects of the real house prices onto consumption in the $\mathrm{US}^{1}$, there is only little evidence on the direct relationship between house prices and output. These include Jud and Winkler (2002),

\footnotetext{
1 The reader is referred to Nyakabawo et al. (2013) for the detailed literature review.
}

Hwang and Quigley (2006), Gallin (2006), Demary (2010), Miller et al. (2011) and Nyakabawo et al. (2013). Jud and Winkler (2002) and Hwang and Quigley (2006) study the dynamics of metropolitan housing prices and find that real house price appreciation is strongly driven by fundamentals including income. In a panel of ten OECD countries including US, Demary (2010) examines the interplay between macroeconomic variables and house prices and concludes that real house prices have a significant effect on the macroeconomic performance including output. Similar result is reported by Miller et al. $(2011)^{2}$ who investigate the effect of house price changes on output in a panel of 379 MSAs. This paper further decomposes house price changes into predictable changes (collateral effect) and unpredictable changes (wealth effect) and concludes that the income effect of house price changes mainly channeled through the collateral effect, at least at the local level. None of these studies, however, considers the nature and the direction of causality between house prices and economic growth.

Recently, Nyakabawo et al. (2013) investigate the time-varying nature of the relationship between house prices and GDP per capita using the bootstrap Granger (temporal) non causality test and a fixed-size rolling-window estimation approach. They find a significant and frequent unidirectional causality running from the real house prices to real GDP per capita with some evidence of temporal bidirectional causality between the two variables. Being at the national level, these findings however assume the homogeneity of local housing markets which may result in potential bias in the estimates (Pesaran 2006). In effect, MSAs differ not only in their economic structure but also in their reactions to external shocks; hence justifying the importance of controlling for MSA-specific characteristics. Considering the herterogeneity in the spatial distribution of wealth, Gallin (2006) investigates the long run relationship metropolitan between house prices and income using both standard time series models and panel cointegration approach and fails to reject the hypothesis of no cointegration. Based on a panel of 95 MSAs, this finding is potentially misleading due to the issue of representativeness as US consists of roughly 400 MSAs.

\footnotetext{
${ }^{2}$ Interestingly, an earlier version of this paper carried out formal Granger causality tests in a panel VAR set-up for the 379 MSAs, concluding unidirectional causality running from GMP to house prices. The working paper version is available at: www.sandiego. edu/business/.../HousePricesandEconomicGrowth.pdf. This is available at: www.sandiego.edu/business/documents/HousePricesandEconomicGrowth.pdf.
} 
This paper employs various panel data techniques to reinvestigate the dynamic relationship between real house prices and real per capita personal income in a panel of 351 MSAs chosen based on available data. It further implements a panel Granger causality approach to assess the causal direction between the two variables. Empirical findings support the existence of the long- run relationship between real house prices and real per capita personal income; the causality running from both directions in the long run as well as in shorter horizon. We conclude that house prices drive personal income at the local level and likewise, per capita personal income can be used to predict local house prices. In the remainder, section 2 describes the data. Section 3 presents the estimation and discusses the main results. Section 4 concludes.

\section{DATA AND PRELIMINARY ANALYSIS}

The analysis is based on annual data for 351 US MSAs for the period from 1993 to 2011. The house prices data come from the Federal Housing Finance Agency (FHFA) and the per capita personal income series are obtained from the Bureau of Economic Analysis (BEA). The two series are deflated by the consumer price index drawn from the Federal Reserve Economic Data (FRED) to obtain real values. The series are further transformed in their $\log$ forms.

Giving that the appropriate specification depends on the time series properties of the variables, it is important to first assess the unit root properties of the series under consideration. If real house prices (lhp) and real per capita personal income (lypc) cointegrate, their relationship is interpreted as a long-run equilibrium and therefore the direction of the causality should be investigated based on the error correction representation. Therefore, we carry out different panel unit root tests which account for unobservables such as heterogeneity and cross-section dependence which, as shown in the following section, have been proven relevant for the present analysis. By relying on a broader set of information, panel unit root tests offer gains in power compared to standard unit root tests which are commonly recognized to deliver low power against stationary alternatives (Campbell, Perron 1991).

\subsection{Heterogeneity and cross sectional dependence tests}

One important issue in panel data analysis consists to decide whether the slope coefficients should vary or not across units. The homogeneity assumption for the parameters may be misleading in the presence of region specific characteristics. In the House prices and economic growth nexus, there may be a significant relationship in some MSAs but not in others. The second issue refers to the possible spatial effect amongst regions. In effect, the high degree of economic and financial integration makes a MSA to be sensitive to the economic shocks in other MSAs. Therefore, cross sectional dependency may play a significant role in characterizing the relationship between metropolitan house prices and income in the US.

\section{Heterogeneity test}

We follow closely the test suggested by Pesaran and Yamagata (2005) who follow the two-step procedure and first run a regression of log real income per capita on the log of housing prices. The residuals from this regression, which we denote by $e$, are then used in the second stage to estimate dynamics of the real income per capita. Specifically:

$$
e_{i t}=a_{i}+\lambda e_{i t-1}+\sigma_{i(e)}+\varepsilon_{i t},
$$

where: within each city $\lambda$ is assumed to be homogeneous across the different housing prices. Our interest is to test the hypothesis that $\lambda=\lambda_{i}$ for all $i$ in $e$. The test results are given in Table 1 . The $\Delta$ statistic and the associated bootstrapped $p$ value leads to strong rejections of the homogeneity hypothesis.

Table 1. Homogeneity test

\begin{tabular}{ll}
\hline$\Delta$ test $=$ & 49.52 \\
\hline Bias-corrected bootstrap p-value $=$ & {$[0.00]$} \\
\hline
\end{tabular}

Cross sectional dependence test

We apply Pesaran's (2004) $C D$ test for balanced samples to test for cross sectional dependence. In particular:

$$
C D=\sqrt{2 T / N(N-1)} \sum_{i=1}^{N-1} \sum_{j=i+1}^{N} \rho_{i j},
$$

where: $\rho_{i j}$ is the sample estimate of the pair-wise correlation of the residuals:

$$
\rho_{i j}=\rho_{j i}=\sum_{t=1}^{T} u_{i t} u_{j t} / \sqrt{\sum_{t=1}^{T} u_{i t}^{2} \sum_{t=1}^{T} u_{j t}^{2}},
$$

and $u$ are the residuals from the panel model. He shows that under the null hypothesis of no crosssectional dependence, $C D \rightarrow N(0,1)$ for $N \rightarrow \infty$ and $T$ sufficiently large. The results show that $C D=52.94$ with p-value [0.00]. As we can see, the $\mathrm{CD}$ test strongly rejects the null hypothesis of no cross-sectional dependence. 
Table 2. Panel unit root tests

\begin{tabular}{llllllll}
\hline Variables & LL & Had (hom) & Had (het) & F-ADF & F-PP & HT & Breit \\
\hline lypc & -1.38 & $31.58^{*}$ & $26.44^{*}$ & 16.59 & 17.29 & -1.61 & -0.71 \\
$\Delta l y p c$ & $-6.29^{*}$ & 1.46 & 1.24 & $124.35^{*}$ & $129.82^{*}$ & $-6.84^{*}$ & $-4.65^{*}$ \\
$l h p$ & -1.42 & $42.59^{*}$ & $42.37^{*}$ & 18.30 & 18.15 & -1.52 & -1.37 \\
$\Delta l h p$ & $-7.14^{*}$ & 1.24 & 1.41 & $126.38^{*}$ & $148.83^{*}$ & $-7.64^{*}$ & $-6.49^{*}$ \\
\hline
\end{tabular}

Notes: $\Delta$ denotes first differences. LL denotes the Levin and Lin test, Had denotes the Hadri test, F-ADF and F-PP denotes the Maddala and Wu test, HT denotes the Harris and Tzavalis test, Breit denotes the Breitung test, $\mathrm{ADF}$ is the Augmented Dickey-Fuller test and PP is the Phillips-Perron test.

*denotes statistical significance at $1 \%$.

\subsection{Panel unit root tests}

There are a variety of panel unit root tests, which include Levin and Lin (1993), Harris and Tzavalis (1999), Maddala and Wu (1999), Breitung (2000) and Hadri (2000). With the exception of Hadri (2000) test, all these tests could not reject the hypothesis that the levels of both variables under study contain a unit root at the $1 \%$ level of significance (see Table 2). When the tests are applied on the first differences of those variables, the reported results display that the unit root hypothesis is rejected. By contrast, in the Hadri (2000) test, the null of stationarity is rejected for both variables.

\section{EMPIRICAL INVESTIGATION}

\subsection{Panel cointegration}

Assume that the hypothesized cointegration relationship between $l h p$ and lypc for each MSA is given by:

$$
l y p c_{i t}=a_{0 i}+a_{1 i} l h p_{i t}+u_{i t},
$$

where: $i=1, \ldots, N$ indexes the MSA, $t=1, \ldots, T$ indexes time and $u$ is the error term.

We test for the presence of a long-run relationship using the Nyblom-Harvey (2000), FisherJohansen (by Maddala, Wu 1999), Pedroni (2001, 2004) and Kao (1999) panel cointegration tests (see Appendix for further details). The panel cointegration test results are presented in Table 3 with the lag length chosen on the basis of the Akaike information criterion (AIC) with individual intercepts

Table 3. Panel cointegration tests and trends. The test results strongly reject the null of no cointegration in favor of the presence of a long-run relationship between income per capital and housing prices in all types of tests considered.

Having established cointegration, we estimate the long-run model using FMOLS (Fully Modified OLS), DOLS (Dynamic OLS), PMGE (Pooled Mean Group Estimator) and MG (Mean Group) methods. The long-run estimations are reported in Table 4. With the inclusion of a time trend the estimated impact of house prices on per capita income, as expected, positive (FMOLS: 0.314; DOLS: 0.296; PMGE: 0.283; MG: 0.264) and statistically significant at the $1 \%$ level. The cointegration results appear to be very robust. The joint Hausman-test can not reject the null hypothesis of poolability of the long-run coefficients.

Table 4. Long-run estimates (lypc is the dependent variable)

\begin{tabular}{lllll}
\hline Coefficients & FMOLS & DOLS & PMGE & MG \\
\hline Constant & 1.238 & 1.224 & 1.327 & 1.310 \\
& $(24.9)^{*}$ & $(14.1)^{*}$ & $(8.54)^{*}$ & $(5.73)^{*}$ \\
$l h p$ & 0.314 & 0.296 & 0.283 & 0.264 \\
& $(18.9)^{*}$ & $(14.5)^{*}$ & $(6.18)^{*}$ & $(5.02)^{*}$ \\
& 0.70 & 0.64 & 0.62 & 0.57 \\
H-test $/ x^{2}$ & 1.22 & 1.34 & 1.26 & 1.52 \\
& {$[0.60]$} & {$[0.48]$} & {$[0.56]$} & {$[0.34]$} \\
\hline
\end{tabular}

Notes: FMOLS (Fully modified OLS), DOLS (Dynamic OLS), PMGE (pooled mean group) and MG (mean group). The reported results include a time trend. H-test denotes the Hausman test for the null hypothesis of poolability of long-run coefficients. Figures in parentheses denote $\mathrm{t}$-statistcs and those in brackets $\mathrm{p}$-values.

* indicates significance at $1 \%$.

\begin{tabular}{|c|c|c|c|c|c|c|}
\hline \multicolumn{2}{|c|}{ Nyblom-Harvey } & \multicolumn{2}{|c|}{ Fisher-Johansen } & \multicolumn{2}{|l|}{ Pedroni } & \multirow{2}{*}{$\begin{array}{l}\text { Kao } \\
\text { F }\end{array}$} \\
\hline $\mathrm{F}$ & $\mathrm{T}$ & Trace & $\operatorname{Max}$ & $\mathrm{F}$ & $\mathrm{T}$ & \\
\hline $16.37 *$ & $14.69^{*}$ & $1785^{*}$ & $1541^{*}$ & $-45.56^{*}$ & $-40.83^{*}$ & $-21.58^{*}$ \\
\hline
\end{tabular}

Notes: $\mathrm{F}$ denotes fixed effects, while $\mathrm{T}$ denotes fixed effects and time trends. * indicates $1 \%$ rejection level. 


\subsection{Causality results}

Having already found long-run equilibrium, we are also interested in examining the direction of causality between the variables. The Autoregressive Distributed Lag (ARDL) model will be employed to test for the causality between real income per capita and housing prices. This specification has the advantage to accommodate both stationary and non stationary variables; hence mitigating unit root pre-testing requirements.

The ARDL $(1,1)$ representation associated to equation (4) is:

$$
\begin{aligned}
& l y p c_{i t}=b_{0 i}+b_{1 i} l h p_{i t}+b_{2 i} l h p_{i t-1}+ \\
& b_{3 i} l y p c_{i t-1}+v_{1 i t} \\
& \text { and } \\
& l h p_{i t}=c_{0 i}+c_{1 i} l y p c_{i t}+c_{2 i} l y p c_{i t-1}+ \\
& c_{3 i} l h p_{i t-1}+v_{2 i t} .
\end{aligned}
$$

Rewritten in terms of adjustment to a long-run equilibrium, the above specification yields the following error correction equations:

$$
\begin{aligned}
& \Delta l y p c_{i t}=\lambda_{1 i} \Delta l h p_{i t}+ \\
& \varphi_{1 i}\left(l y p c_{i t-1}-\alpha_{0 i}-\alpha_{1 i} l h p_{i t}\right)+v_{1 i t}
\end{aligned}
$$

and

$$
\begin{aligned}
& \Delta l h p_{i t}=\lambda_{2 i} \Delta l y p c_{i t}+ \\
& \varphi_{2 i}\left(l h p_{i t-1}-\beta_{0 i}-\beta_{1 i} l y p c_{i t}\right)+v_{2 i t},
\end{aligned}
$$

where: and are the error correction terms for cross section $i$ and and are the average adjustment coefficients which measure how the two variables adjust to deviations from their long-run equilibrium, respectively:

$$
\begin{array}{rlrl}
\lambda_{1 i} & =\frac{b_{1 i}\left(1-b_{3 i}\right)}{b_{1 i}+b_{2 i}} ; & \lambda_{2 i}=\frac{c_{1 i}\left(1-c_{3 i}\right)}{c_{1 i}+c_{2 i}} ; \\
\varphi_{1 i}=-\left(1-b_{3 i}\right) ; & \varphi_{2 i}=-\left(1-c_{3 i}\right) ; \\
\alpha_{0 i}=\frac{b_{0 i}}{1-b_{3 i}} ; & \beta_{0 i}=\frac{c_{0 i}}{1-c_{3 i}} ; \\
\alpha_{1 i}=\frac{b_{1 i}+b_{2 i}}{1-b_{3 i}} ; & \beta_{1 i}=\frac{c_{1 i}+c_{2 i}}{1-c_{3 i}} .
\end{array}
$$

An alternative way of testing for causality is to perform the so-called panel Granger non-causality test (Hurlin, Venet 2001; Hurlin 2004), suitable for cases where the number of cross-sectional units are way bigger than the length of the time series. To test the relationship between two variables in the Granger sense, consider the following linear panel data model:

$$
\begin{aligned}
& \Delta^{\Delta l y p c_{i t}}=\alpha_{1 i}+\sum_{k=1}^{K} \beta_{1 k} \Delta l y p c_{i t-k}+ \\
& \sum_{k=1}^{K} \gamma_{1 k} \ddot{\mathrm{A}} l h p_{i t-k}+\varepsilon_{1 i t} ;
\end{aligned}
$$

$$
\begin{aligned}
& \Delta l y h_{i t}=\alpha_{2 i}+\sum_{k=1}^{K} \beta_{2 k} \Delta l h p_{i t-k}+ \\
& \sum_{k=1}^{K} \gamma_{2 k} \Delta l y p c_{i t-k}+\varepsilon_{2 i t},
\end{aligned}
$$

where: $\alpha_{j i}$ captures the individual specific effect across $i, j=1,2$ and coefficients $\gamma_{j k}$ are implicitly assumed to be constant for all $i$. First, to implement the panel Granger causality test, we need to obtain the estimators for $\beta_{j k}$ and $\gamma_{j k}$. Hurlin (2004) proposes testing the homogeneous non-causality (HNC) null hypothesis against the heterogeneous (that is $H_{0}: \gamma_{j k}=0, \forall i=1, \ldots, N$ ) against the heterogeneous non-causality hypothesis (HENC) (that is $H_{0}: \gamma_{j k}=0, \forall i=1, \ldots, N$ and $\left.\gamma_{j k} \neq 0, \forall i=N_{1+1}, \ldots, N\right)$. HENC allows some but not all of the individuals to Granger cause from $\Delta l h p$ (respectively $\Delta l y p c$ ) to $\Delta l y p c$ (respectively $\Delta l h p$ ). The idea behind Hurlin (2004) is to average the individual Wald statistics associated with the standard Granger HNC tests for units $i=1, \ldots, N$. The empirical results are based on the case of $K=1$, where the strongest causality findings are obtained as well as because critical values for $K=1$ are available.

The empirical findings obtained from the ARDL specification, which in turn, gives us both short- and long-run causalities tend to show that housing prices are the driver for real income per capita (see Table 5). The coefficient of the ECT represents the speed of the adjustment coefficient which measures the speed at which the value of real per capita income comes back to long-run equilibrium, once it violates the long-run equilibrium relationship. This parameter is of particular interest as it has important implications for the dynamics of the system. The negative sign of the estimated speed of the adjustment coefficient is in accordance with the convergence toward long-run equilibrium. The larger the value of this parameter, the stronger is the response of the variable to the previous period's deviation from long-run equilibrium, if any. The value of the ECT parameter, -0.281 , displays a relatively high adjustment toward long-run equilibrium. On the other hand, in the short-run real income per capita causes housing prices, while the same results are reached in the long-run, with a relatively high adjustment toward equilibrium (i.e. $-0.248)$. The empirical findings from the Hurlin (2004) test just confirm the results of short-run causality obtained under the ARDL specification. 
Table 5. Causality test results

\begin{tabular}{|c|c|c|c|}
\hline \multicolumn{4}{|c|}{ Sources of causation } \\
\hline \multicolumn{3}{|c|}{ Short-run } & $\begin{array}{l}\text { Long- } \\
\text { run }\end{array}$ \\
\hline \multicolumn{4}{|c|}{ ARDL test results } \\
\hline & $\Delta l y p c$ & $\Delta l h p$ & $E C T(\varphi)$ \\
\hline \multirow[t]{2}{*}{$\Delta l y p c$} & -- & 63.29 & -0.281 \\
\hline & & {$[0.00]$} & {$[0.00]$} \\
\hline$\Delta l h p$ & 56.04 & $\cdots$ & -0.248 \\
\hline \multicolumn{4}{|c|}{ Hurlin (2004) test results } \\
\hline & $\Delta l y p c$ & $\Delta l h p$ & \\
\hline \multirow[t]{2}{*}{$\Delta l y p c$} & -- & 10.93 & \\
\hline & & {$[0.00]$} & \\
\hline \multirow[t]{2}{*}{$\Delta l h p$} & 14.58 & $\cdots$ & \\
\hline & {$[0.00]$} & & \\
\hline
\end{tabular}

Note: Figures in brackets denote p-values.

\subsection{Robustness check}

Based on the suggestions by an anonymous referee, we control for possible omitted variable bias by including two additional MSA-level variables namely, employment (emp) and population (pop), and two national-level variables namely real SP500 $(s p)$ and the 30 year fixed mortgage rate (mint). Note, we deflate the nominal SP500 index with the CPI. While data on the national level variables again come from the FRED database, the MSA-level data is obtained from the regional accounts of the BEA. The choice of these variables is in line with the literature on house prices and fundamentals (see Miller et al. 2011; Hepşen, Vatansever 2012; Lean, Smyth 2014 for further details). As can be seen from the results reported in Tables B1-B5 in Appendix B, our basic result of a bi-directional causality (as well as that of heterogeneity, cross-sectional dependence, unit root tests and cointegration) continues to be robust even after the inclusion of these four additional variables. Note that, we repeated all the tests including the unit root tests, since due to data availability on employment, unlike in the two variable case, we could only conduct the study on $340 \mathrm{MSAs}$, rather than 351 . However, we could not conduct the causality tests of Hurlin and Venet (2001) and Hurlin (2004), since the test is designed to handle only two variables. In any event, since this test does not control for cross-sectional dependency, but only heterogeneity, we would want to rely more on the results from the ARDL approach.

\section{CONCLUSIONS}

In this paper, we have examined the nature and causal direction of the relationship between house prices and economic growth proxied by per capita personal income for a panel of 351 US MSAs. Real house prices and real per capita personal income are found to be cointegrated, thus indicating the existence of a long-run relationship between house prices and output. Based on ARDL specification that allows for error-correction, Granger causality test indicates that house prices drive personal income in the long-run as well as at shorter horizon. Similarly, real per capita personal income leads real house prices over both long and short horizons; hence supporting the evidence of a bidirectional causality between the two variables, at least at the local level. Note that, our results continue to be robust, when our bivariate system is extended to include additional MSA-level and national-level variables, which the literature suggests as potential predictors of both personal income and real house prices.

Our findings suggest that changes in personal income can predict house price movements and vice versa. The causality from house prices to personal income confirms the important role of house prices in driving business cycle fluctuations, while the causality from personal income to house prices indicates the economic force behind local housing bubbles. Therefore, housing market development might be an efficient strategy to improve household personal income. Note that the conclusions are based on overall information of all the MSAs. One drawback of the analysis is that it is silent regarding the direction or existence of causality for each of the specific cross-sections (MSAs). Recent papers by Kónya (2006) and Emirmahmutoglu and Kose (2011) have tried to address this issue (besides issues of order of integration and cointegration) based on panel bootstrap causality tests, simultaneously controlling for heterogeneity and cross-sectional dependence. The tests developed in this paper can provide information regarding causality for each specific cross-sectional units. However, these tests require the number of timeseries periods $(T)$ to be greater than the number of cross-sectional units $(N)$, which was not possible in our case. In light of this, it would be interesting to check for the robustness of our results at the US state-level (i.e. a lower level of disaggregation), but categorizing the cross-sections as industrial and agricultural states (since given data availability $N$ 
would still be greater than $T$ ), so that we satisfy the requirement of $T$ being greater than $N$, which, in turn, would allow us to provide the causal relationship for each of the specific states, and hence allow for state-specific policy prescriptions. In addition to this, a further robustness check of the results would be to include the real stock price as a third variable in the system.

\section{ACKNOWLEDGMENT}

We would like to thank two anonymous referees for many helpful comments. However, any remaining errors are solely ours.

\section{REFERENCES}

Abraham, J.; Hendershott, P. 1996. Bubbles in metropolitan housing markets, Journal of Housing Research 7: 191-207.

Breitung, J. 2000. The local power of some unit root tests for panel data, in Baltagi, B.; Fomby, T. B.; Hill, R. C. (Eds.), Advances in Econometrics: Nonstationary Panels, Cointegration in Panels and Dynamic Panels 15: 161-178. JAI: Amsterdam. http://dx.doi. org/10.1016/S0731-9053(00)15006-6

Campbell, J. Y.; Perron, P. 1991. Pitfalls and opportunities: what macroeconomists should know about unit roots, in Blanchard, O. J.; Fisher, S. (Eds.). NBER macroeconomic annual, MIT Cambridge, 141201.

Capozza, D. R.; Hendershott, P. H.; Mack, C.; Mayer, C. J. 2002. Determinants of real house price dynamics, NBER Working Paper 9262.

Demary, M. 2010. The interplay between output, inflation, interest rates and house prices: international evidence, Journal of Property Research 27(1): 1-17. http://dx.doi.org/10.1080/09599916.2010.4990 15

Dickey, D. A.; Fuller, W. A. 1981. Likelihood ratio statistics for autoregressive time series with a unit root, Econometrica 49: 1057-1072. http://dx.doi. org/10.2307/1912517

Emirmahmutoglu, F.; Kose, N. 2011. Testing for Granger causality in heterogeneous mixed panels, Economic Modelling 28: 870-876. http://dx.doi.org/10.1016/j. econmod.2010.10.018

Gallin, J. 2006. The long run relationship between house prices and income: evidence from local housing markets, Real Estate Economics 34(3): 417-438. http:// dx.doi.org/10.1111/j.1540-6229.2006.00172.x

Hadri, K. 2000. Testing for stationarity in heterogeneous panel data, Econometric Journal 3: 148-161. http://dx.doi.org/10.1111/1368-423X.00043

Harris, R. D. F.; Tzavalis, E. 1999. Inference for unit roots in dynamic panels where the time dimension is fixed, Journal of Econometrics 91: 201-226. http:// dx.doi.org/10.1016/S0304-4076(98)00076-1
Hepşen, A.; Vatansever, M. 2012. Relationship between residential property price index and macroeconomic indicators in Dubai housing market, International Journal of Strategic Property Management 16(1): 7184. http://dx.doi.org/10.3846/1648715X.2011.602756

Hurlin, C. 2004. Testing Granger causality in heterogeneous panel data models with fixed coefficients. Mimeo: University Paris IX.

Hurlin, C.; Venet, B. 2001. Granger causality tests in panel data models with fixed coefficients. Mimeo: University Paris IX.

Hwang, M.; Quigley, J. M. 2006. Economic fundamentals in local housing markets: evidence from US metropolitan regions, Journal of Regional Science 46(3): 425-453. http://dx.doi.org/10.1111/j.14679787.2006.00480.x

Iacoviello, M. 2011. Housing wealth and consumption, International Finance Discussion Paper 1027, Federal Reserve Board.

Johansen, S. 1991. Estimation and hypothesis testing of cointegration vectors in Gaussian vector autoregressive models, Econometrica 59: 1551-1580. http:// dx.doi.org/10.2307/2938278

Jud, G. D.; Winkler, T. 2002. The dynamics of metropolitan housing prices, Journal of Real Estate Research 23(1-2): 29-45.

Kao, C. 1999. Spurious regression and residual-based tests for cointegration in panel data, Journal of Econometrics 90: 1-44. http://dx.doi.org/10.1016/ S0304-4076(98)00023-2

Kennickell, A. B.; Starr-McCluer, M.; Surette, B. J. 2000. Recent changes in US family finances: results from the 1998 survey of consumer finances, Federal Reserve Bulletin 86(1): 1-29.

Kónya, L. 2006. Exports and growth: Granger causality analysis on OECD countries with a panel data approach, Economic Modelling 23: 978-992. http:// dx.doi.org/10.1016/j.econmod.2006.04.008

Kwiatkowski, D.; Phillips, P. C. B.; Schmidt, P.; Shin, Y. 1992. Testing the null hypothesis of stationarity against the alternative of a unit root: how sure are we that economic time series have a unit root?, Journal of Econometrics 54: 159-178. http://dx.doi. org/10.1016/0304-4076(92)90104-Y

Lean, H. H.; Smyth, R. 2014. Dynamic interaction between house prices and stock prices in Malaysia, International Journal of Strategic Property Management 18(2): 163-177. http://dx.doi.org/10.38 46/1648715X.2014.925006

Levin, A.; Lin, C. F. 1993. Unit root tests in panel data: new results, Discussion Paper No. 56. University of California at San Diego (UCSD).

Maddala, G. S.; Wu, S. 1999. A comparative study of unit root tests with panel data and a new simple test, Oxford Bulleting of Economics and Statistics 61: 631-652. http://dx.doi.org/10.1111/1468-0084.61. $\mathrm{s} 1.13$

Meen, G. 2002. The time series behavior of house prices: a transatlantic divide?, Journal of Housing Economics 11: 1-23. http://dx.doi.org/10.1006/jhec.2001.0307

Miller, N.; Peng, L.; Sklarz, M. 2011. House prices and economic growth, Journal of Real Estate Finance and 
Economics 42(4): 522-541. http://dx.doi.org/10.1007/ s11146-009-9197-8

Nyakabawo, W.; Miller, S. M.; Balcilar, M.; Das, S.; Gupta, R. 2013. Temporal causality between house prices and output in the US: a Bosstrap Rolling-Window approach, Department of Economics Working Paper 2013-29, University of Pretoria.

Nyblom, J.; Harvey, A. 2000. Tests of common stochastic trends, Econometric Theory 16: 176-199. http:// dx.doi.org/10.1017/S0266466600162024

Pedroni, P. 2001. Purchasing power parity tests in cointegrated panels, Review of Economics and Statistics 83: 727-731. http://dx.doi. org/10.1162/003465301753237803

Pedroni, P. 2004. Panel cointegration: asymptotic and finite sample properties of pooled time series tests with an application to the PPP hypothesis, Economics Theory 20: 597-625. http://dx.doi.org/10.1017/ s0266466604203073

Pesaran, M. H. 2004. General diagnostic tests for cross section dependence in panels. University of Cambridge, Faculty of Economics, Cambridge Working Papers in Economics No. 0435.

Pesaran, M. H. 2006. Estimation and inference in large heterogeneous panels with multifactor error structure, Econometrica 74 (4): 967-1012. http:// dx.doi.org/10.1111/j.1468-0262.2006.00692.x

Pesaran, M. H.; Yamagata, T. 2005. Testing slope homogeneity in large panels, CESIFO Working Paper No. 1438.

\section{APPENDIX A. Panel cointegration tests}

Nyblom and Harvey (2000) define the cointegration relationship as the presence of a common stochastic trend in the panel. They postulate the null hypothesis of zero common trends against the alternative of commons trends among the variables and developed a trace based statistic of the form:

$$
\xi r(A)=\operatorname{tr}\left(A S A^{\prime}\right)^{-1} A C A^{\prime},
$$

where: A is the $r \times n$ matrix of pre-specified cointegrating vectors and $S$ represents the non parametric estimator of the spectral density at frequency zero using a Barlett Window as stated by KPSS (Kwiatkowski et al. 1992):

$$
S=\widehat{\Gamma}_{0}+\sum_{j=1}^{m}\left[1-\frac{j}{m+1}\right]\left[\widehat{\Gamma}_{j}+\widehat{\Gamma}_{j^{\prime}}\right] \text {. }
$$

With $m$ the number of lags in the transitory component:

$$
\widehat{\Gamma}_{j}=\frac{1}{T} \sum_{t=j+1}^{T}\left(y_{t}-\bar{y}\right)\left(y_{t-j}-\bar{y}\right)^{\prime}
$$

and $C$ is an estimator of the second moments of partial sums of the time series:

$$
C=\frac{1}{T^{2}} \sum_{i=1}^{T}\left[\sum_{i=1}^{i}\left(y_{t}-\bar{y}\right)\right]^{\prime}
$$

However, the Pedroni (2004) panel cointegration test is built on a system of equations of the following form:

$$
y_{i, t}=\alpha_{i}+\sigma_{i, t}+\beta_{i} x_{i, t}+\varepsilon_{i, t},
$$

where: $y_{i, t}$ and $x_{i, t}$ are region specific observables assumed to be integrated of order one, $i=1, \ldots, N$ and $t=1, \ldots, T$. The potential cointegrating relationships are estimated individually for each cross section by OLS and the unit root test is applied on the residuals from these regressions. More specifically:

$$
\hat{u}_{i, t}=\rho_{i} \hat{u}_{i, t-1}+\sum_{j=1}^{j_{i}} \theta_{i, j} \Delta \hat{u}_{i, t-j}+\psi_{i, t},
$$

where: $\rho_{i}$ is the parameter of interest. Pedroni (2004) provides the Phillips and Perron-type test to test the null of "all of the individuals of the panel are not cointegrated" $\left(\mathrm{H}_{0}: \rho_{i}=1\right)$ against the alternative that "a significant portion of the individuals are cointegrated". By relying on a set of residualbased test statistics for the null of no cointegration that do not pool the slope coefficients of the regression, the Pedroni (2004) test accounts for heterogeneity which is ignored in the Kao (1999) approach.

In fact, the Kao (1999) cointegration test approach is based on pooled Dickey and Fuller (1981) approach to test the same null hypothesis of no cointegration which amounts to $\mathrm{H}_{0}: \rho=1$ against the alternative that $\mathrm{y}$ and $\mathrm{x}$ are cointegrated $\left(\mathrm{H}_{1}\right.$ : $\rho<1)$.

Maddala and Wu (1999) propose an alternative approach to testing for panel cointegration known as (Fisher/Johansen) which combines tests from individual cross sections to compute the full panel statistics. If $\Pi_{i}$ is the p-value from an individual cointegration test for cross section $i$, then under the null hypothesis, the full panel statistic follows a chi-squared distribution of the form:

$$
-2 \sum_{i=1}^{N} \log \left(\Pi_{i}\right) \rightarrow \chi^{2}(2 n),
$$

where: $\chi^{2}$ value is then used for Johansen's (1991) cointegration trace test and maximum eigenvalue test based on Johansen's (1991) maximum likelihood procedure.

\section{APPENDIX B}

Table B1. Homogeneity test

\begin{tabular}{ll}
\hline$\Delta$ test $=$ & 51.38 \\
Bias-corrected bootstrap p-value $=$ & {$[0.00]$} \\
CD test $=$ & 47.88 \\
p-value $=$ & {$[0.00]$} \\
\hline
\end{tabular}


Table B2. Panel unit root tests

\begin{tabular}{llllllll}
\hline Variables & LL & Had (hom) & Had (het) & F-ADF & F-PP & HT & Breit \\
\hline$l y p c$ & -1.38 & $31.58^{*}$ & $26.44^{*}$ & 16.59 & 17.29 & -1.61 & -0.71 \\
$\Delta l y p c$ & $-6.29^{*}$ & 1.46 & 1.24 & $124.35^{*}$ & $129.82^{*}$ & $-6.84^{*}$ & $-4.65^{*}$ \\
$l h p$ & -1.42 & $42.59^{*}$ & $42.37^{*}$ & 18.30 & 18.15 & -1.52 & -1.37 \\
$\Delta l h p$ & $-7.14^{*}$ & 1.24 & 1.41 & $126.38^{*}$ & $148.83^{*}$ & $-7.64^{*}$ & $-6.49^{*}$ \\
$l p o p$ & -1.19 & $36.71^{*}$ & $31.25^{*}$ & 15.82 & 16.84 & -1.53 & -1.16 \\
$\Delta l p o p$ & $-6.73^{*}$ & 1.37 & 1.25 & $113.62^{*}$ & $118.26^{*}$ & $-6.38^{*}$ & $-5.49^{*}$ \\
$l e m p l$ & -1.31 & $40.24^{*}$ & $36.76^{*}$ & 16.47 & 18.57 & -1.45 & -1.48 \\
$\Delta l e m p l$ & $-6.39^{*}$ & 1.18 & 1.11 & $109.83^{*}$ & $130.42^{*}$ & $-6.38^{*}$ & $-6.85^{*}$ \\
& DF-WS & DF-GLS & & & & & \\
mint & $-1.42(3)$ & $-1.38(3)$ & & & & & \\
$\Delta m i n t$ & $-6.53(1)^{*}$ & $-5.94(2)^{*}$ & & & & & \\
$l s p$ & $-1.28(2)$ & $-1.20(3)$ & & & & &
\end{tabular}

Notes: $\Delta$ denotes first differences. LL denotes the Levin and Lin test, Had denotes the Hadri test, F-ADF and F-PP denotes the Maddala and Wu test, HT denotes the Harris and Tzavalis test, Breit denotes the Breitung test, ADF is the Augmented Dickey-Fuller test and PP is the Phillips-Perron test. ADF and PP denote the Augmented DF and the Phillips-Perron tests, respectively. Numbers in parentheses denote the optimal number of lags used in the augmentation of the test regression and were obtained through the Akaike criterion.

* denotes statistical significance at $1 \%$.

Table B3. Panel cointegration tests

\begin{tabular}{|c|c|c|c|c|c|c|}
\hline \multicolumn{2}{|c|}{ Nyblom-Harvey } & \multicolumn{2}{|c|}{ Fisher-Johansen } & \multicolumn{2}{|l|}{ Pedroni } & \multirow{2}{*}{$\begin{array}{l}\text { Kao } \\
\mathrm{F} \\
\end{array}$} \\
\hline $\mathrm{F}$ & $\mathrm{T}$ & Trace & $\operatorname{Max}$ & $\mathrm{F}$ & $\mathrm{T}$ & \\
\hline $23.48^{*}$ & $19.27 *$ & $1916^{*}$ & $1715^{*}$ & $-52.18^{*}$ & $-44.36^{*}$ & $-24.71^{*}$ \\
\hline
\end{tabular}

Notes: $\mathrm{F}$ denotes fixed effects, while $\mathrm{T}$ denotes fixed effects and time trends. * indicates $1 \%$ rejection level.

Table B4. Long-run estimates (lypc is the dependent variable)

\begin{tabular}{|c|c|c|c|c|}
\hline Coefficients & FMOLS & DOLS & PMGE & $\mathrm{MG}$ \\
\hline \multirow[t]{2}{*}{ Constant } & 1.094 & 1.109 & 1.114 & 1.106 \\
\hline & $(16.7)^{*}$ & $(17.5)^{*}$ & $(7.35)^{*}$ & $(5.21)^{*}$ \\
\hline \multirow[t]{2}{*}{$\operatorname{lhp}$} & 0.264 & 0.237 & 0.226 & 0.237 \\
\hline & $(10.4)^{*}$ & $(8.35)^{*}$ & $(5.64)^{*}$ & $(5.37)^{*}$ \\
\hline \multirow[t]{2}{*}{ lpop } & 0.105 & 0.112 & 0.118 & 0.122 \\
\hline & $(6.74)^{*}$ & $(7.34)^{*}$ & $(6.59)^{*}$ & $(6.19)^{*}$ \\
\hline \multirow[t]{2}{*}{ lempl } & 0.316 & 0.337 & 0.363 & 0.348 \\
\hline & $(7.52)^{*}$ & $(6.94)^{*}$ & $(6.59)^{*}$ & $(5.84)^{*}$ \\
\hline \multirow[t]{3}{*}{$\operatorname{mint}$} & -0.139 & -0.164 & -0.182 & -0.173 \\
\hline & $(-6.48)^{*}$ & $(-6.83)^{*}$ & $(-7.11)^{*}$ & $(-6.58)^{*}$ \\
\hline & 0.77 & 0.69 & 0.68 & 0.64 \\
\hline \multirow[t]{2}{*}{ H-test $/ x^{2} d f$} & 1.34 & 1.45 & 1.33 & 1.72 \\
\hline & {$[0.51]$} & {$[0.40]$} & {$[0.49]$} & {$[0.28]$} \\
\hline
\end{tabular}

Notes: FMOLS (Fully modified OLS), DOLS (Dynamic OLS), PMGE (pooled mean group) and MG (mean group). The reported results include a time trend. H-test denotes the Hausman test for the null hypothesis of poolability of long-run coefficients. Figures in parentheses denote t-statistcs and those in brackets p-values.

* indicates significance at $1 \%$. 
Table B5. Causality test results

\begin{tabular}{|c|c|c|c|c|c|c|}
\hline \multicolumn{7}{|c|}{ Sources of causation } \\
\hline \multicolumn{6}{|c|}{ Short-run } & Long-run \\
\hline \multicolumn{7}{|c|}{ ARDL test results } \\
\hline & $\Delta l y p c$ & $\Delta l h p$ & $\Delta p o p$ & $\Delta e m p l$ & $\Delta \operatorname{mint}$ & $\operatorname{ECT}(\varphi)$ \\
\hline \multirow[t]{2}{*}{$\Delta l y p c$} & -- & 56.78 & 49.73 & 56.17 & 39.84 & -0.246 \\
\hline & & {$[0.00]$} & {$[0.00]$} & {$[0.00]$} & {$[0.00]$} & {$[0.00]$} \\
\hline \multirow[t]{2}{*}{$\Delta l h p$} & 64.82 & -- & 51.20 & 49.13 & 41.28 & -0.185 \\
\hline & {$[0.00]$} & & {$[0.00]$} & {$[0.00]$} & {$[0.00]$} & {$[0.00]$} \\
\hline \multirow[t]{2}{*}{$\Delta p o p$} & 15.37 & 4.49 & --- & 42.47 & 1.36 & -0.139 \\
\hline & {$[0.06]$} & {$[0.39]$} & & {$[0.00]$} & {$[0.64]$} & {$[0.00]$} \\
\hline \multirow[t]{2}{*}{$\Delta e m p l$} & 62.19 & 52.38 & 36.81 & -- & 40.93 & -0.168 \\
\hline & {$[0.00]$} & {$[0.00]$} & {$[0.00]$} & & {$[0.00]$} & {$[0.00]$} \\
\hline \multirow[t]{2}{*}{$\Delta \operatorname{mint}$} & 2.03 & 30.14 & 0.73 & 1.74 & --- & \\
\hline & [0.55] & {$[0.00]$} & {$[0.82]$} & {$[0.59]$} & & {$[0.00]$} \\
\hline
\end{tabular}

Notes: Figures in brackets denote p-values. 